\title{
A study of Phosphate Adsorption characteristics on different soils
}

\author{
Mallikarjun. S. D ${ }^{1}$, Dr S. R. Mise ${ }^{2}$ \\ ${ }^{1}$ PDA College of Engineering Gulbarga-585102, Karnataka State, INDIA \\ ${ }^{2}$ PDA College of Engineering Gulbarga-585102, Karnataka State, INDIA
}

\begin{abstract}
In this research, adsorption of Phosphate (p-Adsorption) on Black cotton Soil and Red soil has been studied through using batch adsorption techniques. Main objectives of this study are, to study the physical properties of Black cotton soil and Red soil, detection of Phosphate removal by adsorbent as a function of contact time, adsorbent dosage and $\mathrm{pH}$, to study sorption kinetics, to study column tracer experiment and isothermal pattern. The results of this study showed that the Optimum contact time, dosage and $\mathrm{pH}$ for adsorption of Phosphate on Black cotton soil and Red soil reached to equilibrium after 55mins and 60mins, with removal efficiency of (86\%), 1000mg and $1200 \mathrm{mg}(66 \%$ and $70 \%)$ as optimum dosages. Higher adsorption of Phosphate was observed at higher $\mathrm{pH}$, obtained at $\mathrm{pH} 8.0$ and 8.5, (62.5\% and 64\%). The rate of adsorption of Phosphate obeys first order rate equation. The obtained results of the batch and column experiments are best fit to Langmuir and Freundlich adsorption isotherms. From the experimental analysis it is concluded that Black cotton soil and Red soil shows good removal efficiency and hence can be used as adsorbents.
\end{abstract}

Keywords: - P-Adsorption, characteristics, Batch Experiments, Freundlich Isotherm, Langmuir Isotherm, Column tracer experiments

\section{INTRODUCTION}

For the first time in this entire cultural history, man is facing one of the most horrible ecological crises the problem of pollution of his environment, which in the past was pure, virgin, undisturbed, uncontaminated, and basically quite hospitable for him ${ }^{[1]}$. Waste disposal from various industries, municipal dumping in the urban areas and increased use of chemical fertilizers, pesticides and irrigation water are of great environmental concern .The residues of fertilizers, pesticides and irrigation water in one hand, increased agricultural production; while, on the other hand, created adverse impact on soil and water bodies ${ }^{[1]}$. Many causes of pollution including sewage and fertilizers contain nutrients such as phosphates. In excess levels, nutrients over stimulate the growth of aquatic plants and algae. Excessive growth of these types of organisms consequently clogs our waterways, use up dissolved oxygen as they decompose, and block light to deeper waters. This, in turn, proves very harmful to aquatic organisms as it affects the respiration ability of fish and other invertebrates that reside in water. The pollution of lakes, rivers and streams with chemical contaminants has become one of the most crucial environmental problems within the 20th century. Waterborne chemical pollution entering rivers and streams cause tremendous amounts of destruction. Pollution is caused when silt and other suspended solids, such as soil, wash off plowed fields, construction and logging sites, urban areas, and eroded river banks when it rains. Under natural conditions, lakes, rivers, and other water bodies undergo Eutrophication, an aging process that slowly fills in the water body with sediment and organic matter. When these sediments enter various bodies of water, fish respiration becomes impaired, plant productivity and water depth become reduced, and aquatic organisms and their environments become suffocated. Pollution in the form of organic material enters waterways in many different forms as sewage, as leaves and grass clippings, or as runoff from livestock feedlots and pastures. When natural bacteria and protozoan in the water break down this organic material, they begin to use up the oxygen dissolved in the water. Many types of fish and bottom-dwelling animals cannot survive when levels of dissolved oxygen drop below two to five parts per million. Animal wastes are high in oxygen demanding material, nitrogen and phosphorus, and they often harbor pathogenic organisms. Wastes from commercial feeders are contained and disposed of on land; their main threat to natural waters, therefore, is from runoff and leaching. ${ }^{[2]}$

The budgeting of phosphorus fertilizer has received less attention than nitrogen fertilizer. The high doses of phosphorus applied to freely draining soil immediately followed by heavy rainfall causes some phosphorus losses through volatilization and leaching processes ${ }^{[3]}$. Phosphorus fertilizer loss is heavily implicated in water course pollution and freshwater Eutrophication. Thus once ecosystems are contaminated by these elements, they become potential threat for many years. Their accumulation reduces soil fertility; soil microbial activity, and plant growth, as well as, the quality of agricultural products ${ }^{[1]}$. It is observed that when an element is applied to soil, some of it may be leached, some may be retained by the soil particles, some may be lost from the soil other than leaching loss, some may be incorporated by soil microorganisms or some may be taken up by plant. 
In most cases, several contaminants are simultaneously released into the environment. Therefore, it is of crucial importance to study in detail the mutual influence of the different minerals in soil retention process. Soil has an important role in Phosphate accumulation, retarding the migration process, which influences further ground- and surface water contamination process.

The retardation factor $(R)$ is one of the coefficients that describe the migration abilities of particular components in groundwater. It shows how many times the migration of the substance subjected to adsorption slower than the actual speed of water flow in pores ${ }^{[4]}$. The retardation factor can be evaluated by laboratory methods, determining the adsorption isotherms of the migrating substances, or by field observations of the speed of substance migration.

Due to availability of water from upper Krishna project irrigation is extensively followed by the farmers, where phosphates pollution is caused due to the use of fertilizers and pesticides. In our area available soils are Red soil, Black cotton soil. The objectives of the work are, to study the retention and leaching of different types of soils available in the area, mainly Red, BLACK COTTON soil. Determining the maximum amount of phosphate adsorbed under mono element condition, and to evaluate the potentials for these mineral to migrate through these soils during groundwater percolation. To perform a set of Batch experiments to obtain Retardation factors for Phosphate for the above mentioned two types of soils by fitting the experimental results to analytical equations given by Langmuir and Freundlich isotherms. To perform Colum Tracer experiments and to study the movement pattern by Break through curves of Phosphate on the two soils.

\section{MATERIALS AND METHODS}

Soil samples of two different series viz. Red \& Black were collected from different locations of Bidar, as they are locally available in Bidar region. All the two soils are moderately acidic in nature. Red and Black Cotton series are developed on medium to moderately fine textured soils.

\subsection{Soils Studied}

2.1.1 Black soil

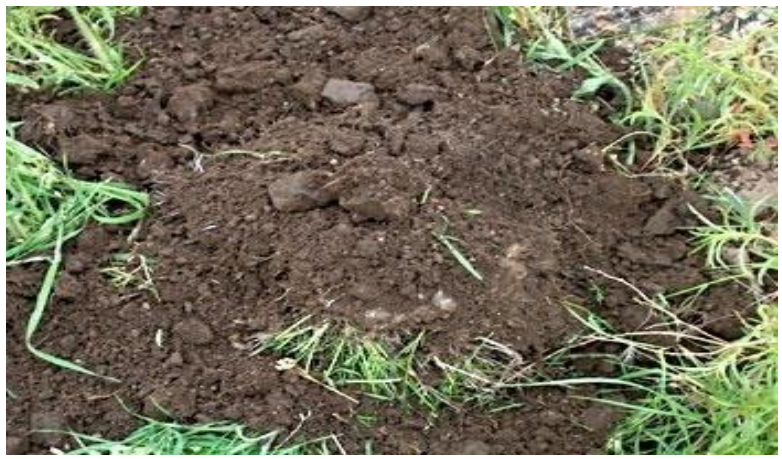

Figure 2.1.black cotton soil

Black soils are also known as regur soils. They are black in color as suggested by the name. The color of the soil is black because of the presence of certain salts. However, in some places, presence of humus in the soil imparts its black color. This soil becomes sticky when is wet owing to the high quantity of clay deposition. Black soils are generally thin and sandy in the hilly regions of the country. It does not contain adequate nitrogen but it contains sufficient phosphorus required for the growth of plants as shown in "Fig. 2.1".

\subsubsection{Red and Yellow soils}

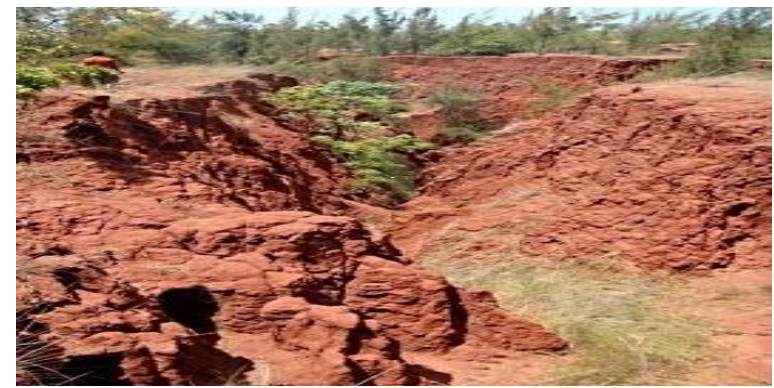

Figure 2.2 Red and yellow soils

www.iosrjen.org 
Red and Yellow soils are found in areas, which receive low rainfall. They generally develop on metamorphic rocks. They contain huge concentration of iron oxides that are responsible for giving the reddish or yellow color as shown in "Fig. 2.2" They are less clayey and sandier and are poor in important minerals like lime phosphorous and nitrogen. Red soil is acidic like that of the Lateritic soil. This soil is mainly cultivated during the monsoon rainy season. Red soils also develop in Manipur, Shillong Plateau and Mizoram. ${ }^{[5]}$

\subsection{Soil Characterization}

The different soils namely Red, Black generally available in the area are collected and their physical and chemical parameters are determined. $\mathrm{pH}$ density and particle size distribution of the soils were determined and listed in "Table 2.1" The top soil of 10-20 cm was cleared and the samples of soil were collected by driving the cores into the soil. The samples were air dried and sieved through a $2.0 \mathrm{~mm}$ sieve then mixed thoroughly and stored for further Batch and Tracer column experiments.

Table2.1: Main Soil Characteristics ${ }^{[6]}$

\begin{tabular}{|c|c|c|c|c|}
\hline Sl. No & Characteristics & Black cotton Soil & Red soil & Unit \\
\hline 1 & Moisture content & 7.39 & 5.23 & $\%$ \\
\hline 2 & Surface area & 650 & 375 & $\mathrm{~m}^{2} / \mathrm{gm}$ \\
\hline 3 & $\begin{array}{c}\text { Clay fraction silt } \\
\text { fraction }\end{array}$ & 75.64 & 60.24 & - \\
\hline 4 & Sand fraction & 24.36 & 39.76 & - \\
\hline 5 & $\mathrm{pH}$ & 7.5 & 7.6 & $\mathrm{gm} / \mathrm{m}^{3}$ \\
\hline 6 & Specific gravity & 2.25 & 2.96 & $\mathrm{gm} / \mathrm{cm}^{3}$ \\
\hline 7 & Bulk density & 1.538 & 1.76 & - \\
\hline 8 & Porosity & 0.5 & 0.6 & \\
\hline
\end{tabular}

\subsection{Adsorption Isotherms}

Adsorption isotherms are developed by exposing a given amount of adsorbate in a fixed volume of liquid to varying amounts of adsorbate. Equations that are often used to describe the experimental isotherm data were developed by Freundlich \& Langmuir.

\subsubsection{Freundlich Isotherm}

Of the above mentioned isotherms Freundlich isotherm is used most commonly to describe the adsorption characteristics, derived empirically in 1912, the Freundlich isotherm is defined as follows in the below "Fig. 2.3".
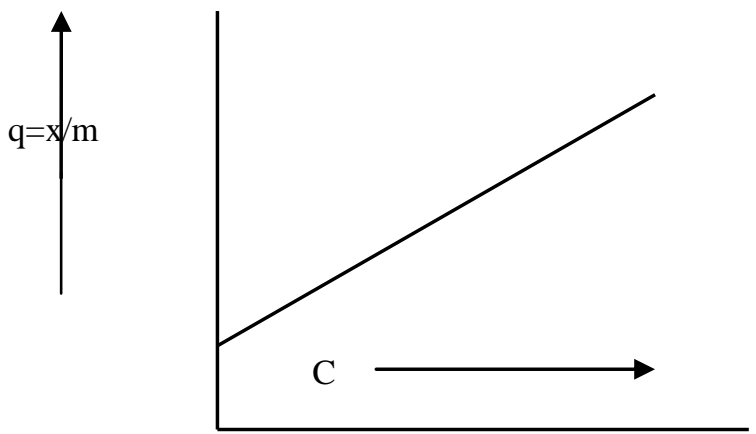

Figure 2.3. Linear form for graphical representation of freundlich isotherm equation 
The general form of Freundlich equation is,

$\mathrm{q}=\left(\frac{\mathrm{x}}{\mathrm{m}}\right)=\mathrm{KC}^{\frac{1}{\mathrm{n}}}$

Where,

$(\mathrm{X} / \mathrm{m})=$ Amount of solute adsorbed per unit mass of adsorbent in $\mathrm{mg} / \mathrm{g}$

$\mathrm{C}=$ Equilibrium concentration of adsorbate in solution after adsorption in $\mathrm{mg} / \mathrm{L}$

$\mathrm{K}=$ Freundlich capacity factor and $(1 / \mathrm{n})=$ Freundlich intensity factor

The constants ' $\mathrm{K}$ ' and ' $\mathrm{n}$ ' in the "equation (1)" can be evaluated by plotting amount of solute adsorbed per unit mass of adsorbent versus equilibrium concentration of adsorbate in solution after adsorption on a double logarithmic graph. The Freundlich equation is basically empirical but is often useful as means for data description. Data are usually fitted to the logarithmic form of equation.

$\log _{\mathrm{e}}(\mathrm{x} / \mathrm{m})=\log _{\mathrm{e}} \mathrm{K}+1 / \mathrm{n} \log _{\mathrm{e}} \mathrm{C}$

As shown in the above, graph is plotted with $\log (\mathrm{x} / \mathrm{m})$ to $\log \mathrm{C}$ gives a straight line with a slope $1 / \mathrm{n}$ and intercept value $(\mathrm{x} / \mathrm{m})$ when $\mathrm{C}=1$. Smaller value of $1 / \mathrm{n}$ points out a better adsorption mechanism and formation of relatively stronger between adsorbate and adsorbent. If $1 / n<1$, bond increases with surface den sity, if $1 / n>1$, bond decreases with surface density and if $1 / n=1$ surface sites are open in order to generate the equilibrium data $(\mathrm{mg} / \mathrm{L})$.

\subsubsection{Langmuir Isotherm}

Langmuir isotherm is based on the assumption that point of valance exists on the surface of the adsorbent and that each of these site is capable of adsorbing one molecule. It is assumed that the adsorption sites have equal affinities for molecules of adsorbate and that the presence of adsorbed molecules at one site will not affect the adsorption of molecules at an adjacent site

The Langmuir equation is commonly written a $q=\left(\frac{x}{m}\right)=\frac{a b C}{1+b C}$

$$
\frac{C}{x / m}=\frac{1}{a b}+\frac{C}{a}
$$

Where, $\mathrm{q}=$ Amount of solute adsorbed per unit mass of adsorbent in $\mathrm{mg} / \mathrm{g}, \mathrm{C}=$ Equilibrium concentration of adsorbate in solution after adsorption in $\mathrm{mg} / \mathrm{L}$ and ' $\mathrm{a}$ ' and ' $\mathrm{b}$ ' are Langmuir constants related to capacity and energy of adsorption respectively.

Plot of ' $\mathrm{q}$ ' vs 'C' would give the value of constants. A dimensionless equilibrium parameter called separation factor, $\mathrm{R}$ is use to study the applicability of Langmuir adsorption isotherm. This is defined by Webber and Chakarvarthi

$\mathrm{R}=\frac{1}{(1+\mathrm{a}) \mathrm{C}_{0}}$

Where, $\mathrm{a}=$ Langmuir constant, $\mathrm{C}_{0}=$ initial concentration, $\mathrm{R}=$ Separation factor

From the above equation Webber and Chakarvarthi given parameter indicating the shape of the isotherm are as follow.

$\begin{array}{lc}\text { Values of } \mathrm{R} & \text { Type of isotherm } \\ \mathrm{R}>1 & \text { unfavorable } \\ & \\ \mathrm{R}=1 & \text { linear } \\ 0<\mathrm{R}>1 & \text { favorable } \\ \mathrm{R}=0 & \text { irreversible }\end{array}$




\subsection{Determination of Phosphate}

In acidic condition, orthophosphate reacts with ammonium molybdate to form molybdophosphoric acid. It is further reduced to molybdum blue by adding reducing agent such as stannous chloride or ANSA. The intensity of the blue colored complex is measured which is directly proportional to the concentration of the phosphate present in the sample.

\subsection{Column Tracer Experiments}

To observe the retention and leaching of phosphate through soil, Soil columns of length $30 \mathrm{~cm}$ was used. For the column, glass column of $4 \mathrm{~cm}$ diameter was used. The length of the soil columns were chosen on the basis of soil texture and compaction. At the bottom, a height $6 \mathrm{~cm}$ was filled by sand. Outlets were made at the bottom of the column to collect the leachate. First the water was allowed to leach through the column to saturate the soil and then the phosphate solution was passed through the saturated soil, in single flow. The leachate was collected for every $1 / 2$ hours and tested for phosphate concentrations. "Fig. 2.4" shows the column experimental arrangement.

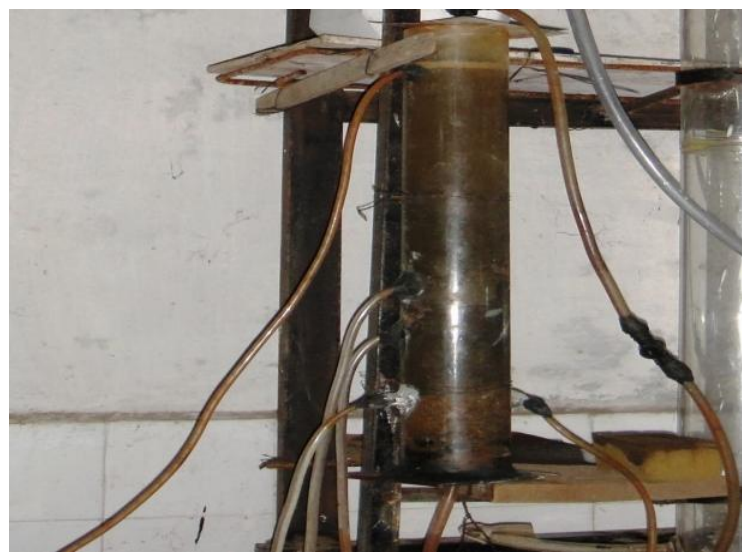

Figure 2.4. Soil column equipment

For the preparation of tracer solution $\mathrm{KH}_{2} \mathrm{PO}_{4}$ had been used to obtain the following concentrations: $1000 \mathrm{mg} / \mathrm{L}$ of P. The column preparation has been based on manual soil compaction methodology ${ }^{[7]}$.

\section{RESULTS AND DISCUSSIONS}

A series of Batch and Tracer column experiments have been performed to determine the adsorption of Phosphates on the locally available soils: namely Red and Black cotton Soil. The experimental results obtained are compared to analytical adsorption equations to obtain retardation and adsorption parameter.

\subsection{Results of Batch Experiments}

The main objective of the batch experiments was to obtain the value of maximum adsorption capacity for each tracer in the locally available soils. For that purpose, and as the aim of the study was to analyze the adsorption phenomena, all batch experiments were done by adding the three tracers solution to each soil in different concentrations. For each soil, the five tracer concentrations have been used to perform the Batch experiments. Following results show the linear relation between 1/Q and 1/C used to obtain the values of Langmuir constants ' $a$ ' and ' $k$ '. The results are also fit to Freundlich power equation to obtain the parameters ' $\mathrm{K}_{\mathrm{f}}$ ' and ' $\mathrm{C} \mathrm{e}_{\mathrm{e}}$ '.

\subsection{Batch Sorption Experiments}

3.2.1 Effect of contact time

Contact time has great influence on the adsorption process. The effects of contact time on the adsorption of phosphate on Black cotton soil \& Red soil were shown in "Fig 3.1" respectively. From the graph it is observed that the extent of phosphate adsorption increases with increase in time and attain equilibrium at particular time. The adsorption curves are characterized by sharp rise initial stage and decrease near equilibrium. From the graph after equilibrium further increase in time adsorption is not changing hence the optimum contact time for Black cotton soil is $55 \mathrm{mins}$ and Red soil is $60 \mathrm{mins}$. 
Initial concentration of phosphate $\mathrm{C}_{0}=5 \mathrm{mg} / \mathrm{L}$

Dosage $=1000 \mathrm{mg}, 1200 \mathrm{mg}$, Temperature $=32^{\circ} \pm 1^{\circ}$

$\mathrm{pH}=8.0,8.5$

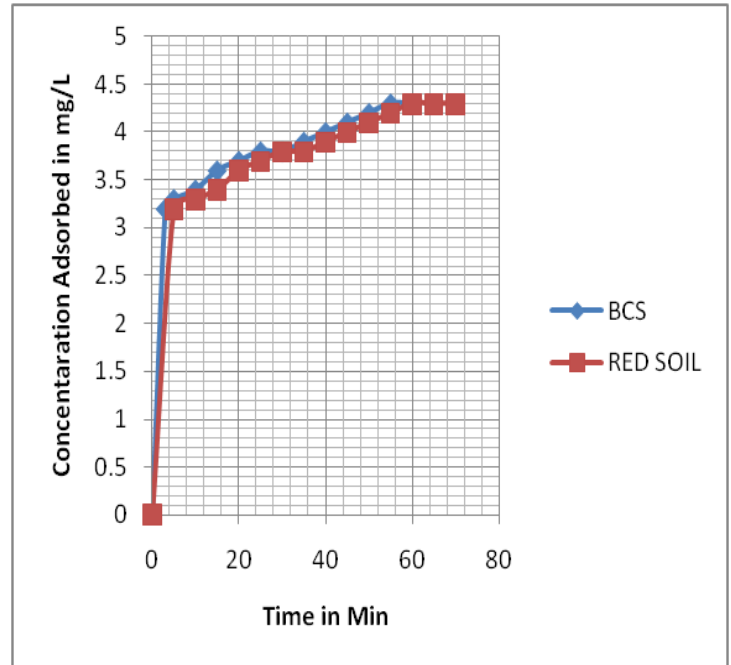

Figure 3.1. Effect of contact time of phosphate on black cotton soil \& red soil

\subsubsection{Effect of adsorbent dosage}

Adsorption is a process in which there is continuous transfer of solute from solution to adsorbent until residual concentration of solution maintains equilibrium with that adsorbed by the surface of adsorbent at constant contact time. Effect of adsorbent dosage is studied and graph of phosphate removal verses dosage is plotted as shown in Fig 3.2 from the graph it is observed that, as the dose of Black cotton soil and Red soil increases, amount of residual phosphate decreases sharply and attains minimum. The point where maximum removal is attained is taken as optimum dosage. After this, not much change in adsorption is observed even after increase in the amount of different soil. Initial concentration of phosphate $\mathrm{C}_{0=} 5 \mathrm{mg} / \mathrm{L}$, Dosage $=1000 \mathrm{mg}$, Contact Time $=55 \mathrm{~min}, 60 \mathrm{~min} \& \mathrm{pH}=8.0,8.5$, Temperature $=32^{\circ} \pm 1^{\circ} \mathrm{C}$

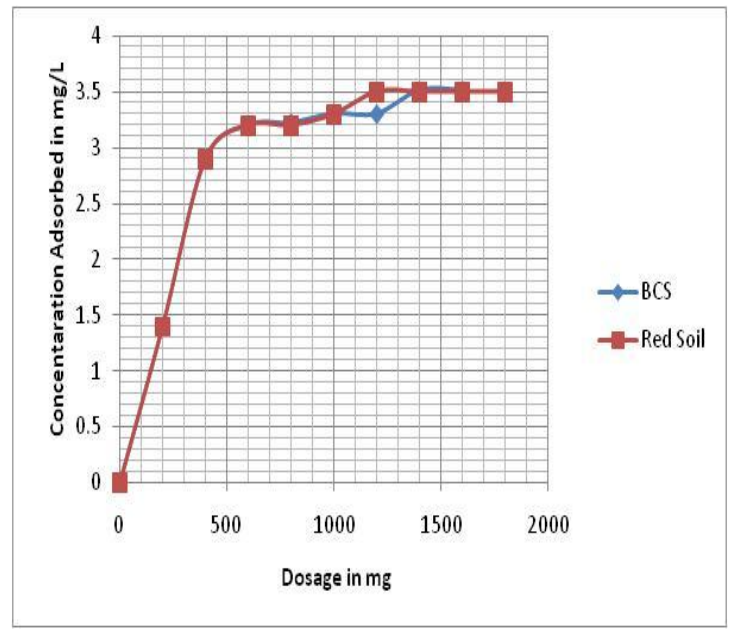

Figure 3.2. Effect of optimum dosage of phosphate on black cotton soil \& red soil

\subsubsection{Effect of $\mathrm{pH}$}

The impact of phosphate removal is depends on $\mathrm{pH}$ of the medium. The graph of $\mathrm{pH}$ against phosphate removal at constant time and dosage is shown in "Fig 3.3", it is observed from the graph that, phosphate removal is not only depends on surface area, time and dosage but also depends on $\mathrm{pH}$. Initial concentration of phosphate $\mathrm{C}_{0}=5 \mathrm{mg} / \mathrm{L}$, Dosage $=1000 \mathrm{mg} / \mathrm{L}, 1200 \mathrm{mg} / \mathrm{L}$ Temperature $=32^{\circ} \pm 1^{\circ} \mathrm{c}$ \& Contact time $=55$ minutes, 60minutes. 


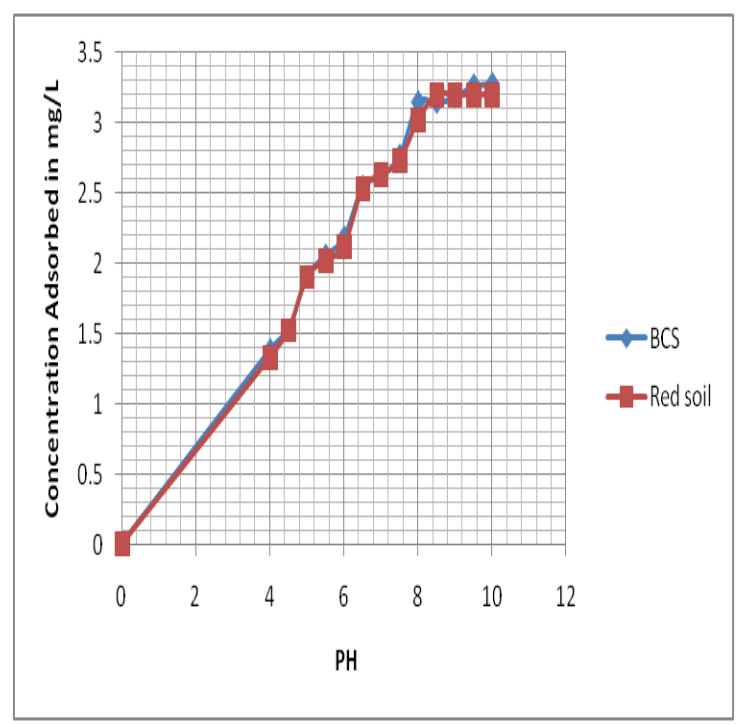

Figure 3.3. Effect of ph of phosphate on black cotton soil \&red soil

\subsection{Sorption Kinetics}

The kinetics of Phosphate removal was performed at constant temperature (i.e. $32 \pm l^{\circ} \mathrm{C}$ ) at different time interval of adsorption. The batch kinetic data for the adsorption of Phosphate was tested for the first order reaction. The rate for the first order reaction is given by Levenspeil.

$$
\begin{aligned}
& \text { In } \mathrm{Ca} / \mathrm{Co}=\mathrm{kt} \\
& \text { Or } 2.303 \log \mathrm{a} /(a-x)=\mathrm{kt} \\
& \text { Or } \log \mathrm{a} /(a-x)=\mathrm{k} / 2.303 \mathrm{t} \\
& \text { Or k=2.303/t log a/ (a-x) }
\end{aligned}
$$

Where, $\mathrm{X}=$ Amount of Phosphate adsorbed at any time t, $(a-x)=$ Residual amount of Phosphate \& $\mathrm{k}=$ Rate constant

This is equation of the type $\mathrm{y}=\mathrm{mx}$, Where, $\mathrm{y}=\log \mathrm{a} /(a-x)$, and $\mathrm{x}=\mathrm{t}$

This produces a straight line graph with slope $\mathrm{k} / 2.303$. From the vales of graphical and calculated " $\mathrm{k}$ " values, it is observed that adsorption of Phosphate follows first order rate equation. The resulting graph is as shown in the "Fig 3.4".

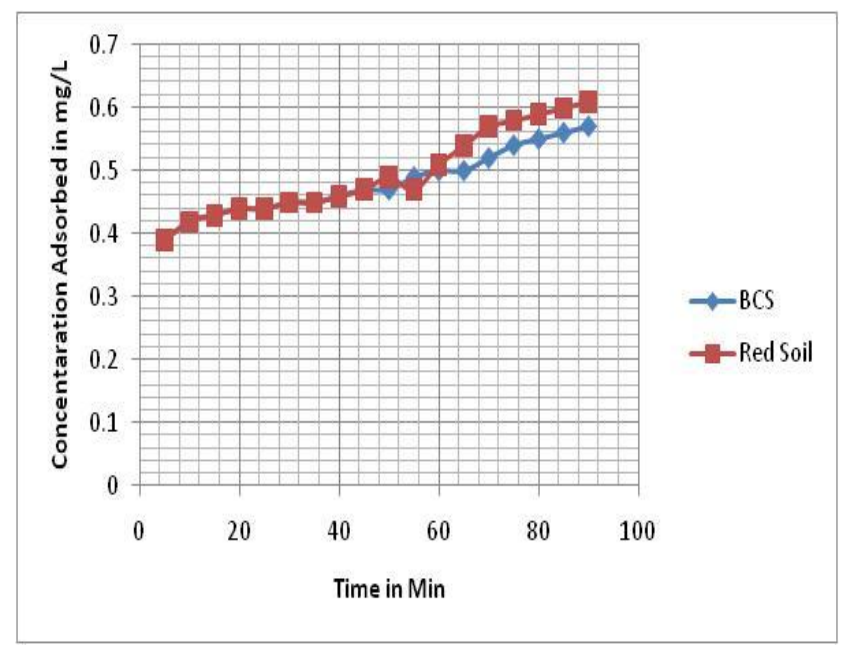

Figure 3.4. Reaction rate constant of phosphate adsorption by black cotton coil \& red soil 
A study of Phosphate Adsorption characteristics on different soils

\subsection{Single Adsorption of Phosphate}

3.4.1 Black Cotton soil

The batch experiments were carried out on Black cotton soil of the properties given in "Table 3.1", with the tracer concentrations of $5,10,15$ and $20 \mathrm{mg} / \mathrm{L}$ respectively.

Table 3.1. Retardation Factor for Tracer Experiment Using Freundlich and Langmuir Isotherm

\begin{tabular}{|c|c|c|}
\hline \multicolumn{3}{|c|}{ Black Cotton Soil } \\
\hline \multirow{4}{*}{ Phosphate } & Langmuir & Freundlic \\
\hline & $a=12.777$ & $K=0.544$ \\
\hline & $\mathrm{b}=0.031$ & $1 / \mathrm{n}=4.66$ \\
\hline & $\mathrm{R}=0.014$ & $\mathrm{n}=0.214$ \\
\hline \multicolumn{3}{|c|}{ Red Soil } \\
\hline \multirow{3}{*}{ Phosphate } & $a=30.00$ & $\mathrm{~K}=0.477$ \\
\hline & $b=0.00416$ & $1 / n=1$ \\
\hline & $R=0.00645$ & $\mathrm{n}=1$ \\
\hline
\end{tabular}

The results of the Phosphate test on Black cotton soil to fit the results to the Langmuir isotherm. The results are plotted as shown in "Fig 3.5" and are fit to "equation (5)" which gives: $\frac{1}{Q}=0.029 \frac{1}{C}+0.0049$, where the regression coefficient $\mathrm{R}=0.014$; from the fit we obtained maximum adsorption and Langmuir constants, ${ }^{\prime} \mathrm{a} \mathrm{A}^{\prime}=12.77$ and ${ }^{\mathrm{b}} \mathrm{b}=0.031$.

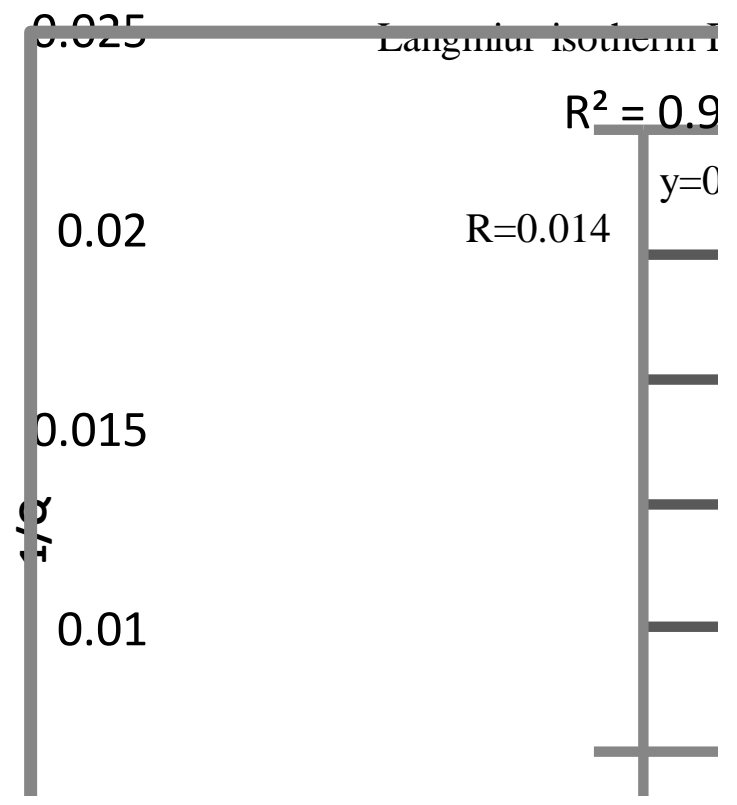

Figure 3.5. Single adsorption of phosphate on black soil 


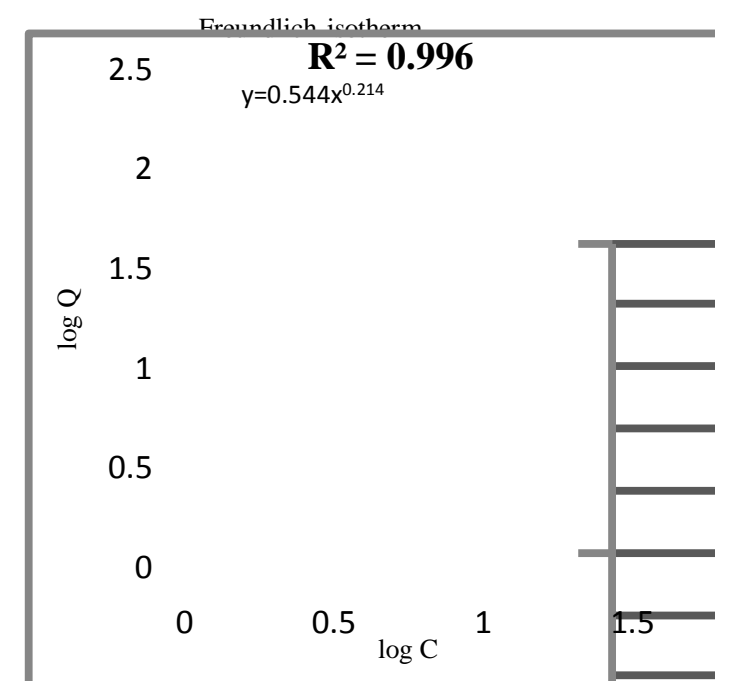

Figure 3.6. Single adsorption of phosphate on black soil

The same experimental results are fit to Freundlich power equation given by "equation 2", by plotting 'Q' vs. 'C' as shown in above "Fig 3.6" and fitting we obtain ' $q e^{\prime}=0.554 C_{e} 0.214$ Which gives $(1 / n)=4.66$ and ' $\mathrm{K}_{\mathrm{f}}=0.544$

Where, $\mathrm{q}_{\mathrm{e}}=(x / \mathrm{m})=$ Amount of solute adsorbed per unit mass of adsorbent in $\mathrm{mg} / \mathrm{kg}, \mathrm{C}_{\mathrm{e}}=$ Equilibrium concentration of adsorbate in solution after adsorption in $\mathrm{mg} / \mathrm{L}$, \& Freundlich capacity factor and $1 / \mathrm{n}=$ Freundlich intensity factor.

In this equation $1 / n>1$, therefore bond decreases with surface density. Similarly the graphs are plotted for Red soil respectively.

\subsection{Column Tracer Experiments}

A series of column tracer experiments as explained in "section 2.5" have been performed with Phosphates on the three different soils considered to obtain the breakthrough curves and retardation coefficients. Results obtained by Column tracer method were interpreted using Freundlich, and Langmuir linear formulas describing the adsorption isotherms. In all cases of phosphate adsorption, the best fit was obtained for the Freundlich isotherm, described by the formulae:

$$
\mathrm{C}_{\mathrm{ads}}=\mathrm{K}^{\mathrm{F}} \times \mathrm{C}_{\mathrm{aq}}^{1 / 2}
$$

Where, $C a d s=$ balance concentration of the studied compound in the ground, $C a q=$ balance concentration of the studied compound in the water \& ' $K F^{F}$ and ' $n$ ' $=$ coefficients of the Freundlich adsorption isotherm.

Substitute distribution coefficient (determined using the Freundlich isotherm) $\mathrm{K}_{\mathrm{d}}{ }^{\mathrm{F}}$ for a given value of balance concentration of ion adsorbed in the solution equals

$$
K_{d}^{F}=\frac{K^{F} C_{a q}^{1 / n}}{C_{a q}}=K^{F} C_{a q}^{(1 / n-1)}
$$

For the distribution coefficient determined on the basis of the adsorption isotherm, the retardation has been

defined $\quad R=1+\frac{\rho_{d}}{n} K_{d}^{F}$

\subsection{Single Adsorption of Phosphate}

\subsubsection{Black Cotton Soil}


A study of Phosphate Adsorption characteristics on different soils

A series of column tracer experiments have been performed on Black cotton soil and the "Fig. 3.7" shows tracer breakthrough curve for $2 \mathrm{mg} / \mathrm{L}$ of initial concentration. The results obtained with different concentrations are fit to Adsorption isotherms as follows.

Similar experiments were performed for concentrations of 5 and $10 \mathrm{mg} / \mathrm{L}$, the results of the tracer experiment are fit to Freundlich and Langmuir isotherms as shown in below "Fig 3.8, 3.9" and the results are analyzed. Similarly the graphs are plotted \& the results are analyzed for red soil respectively.

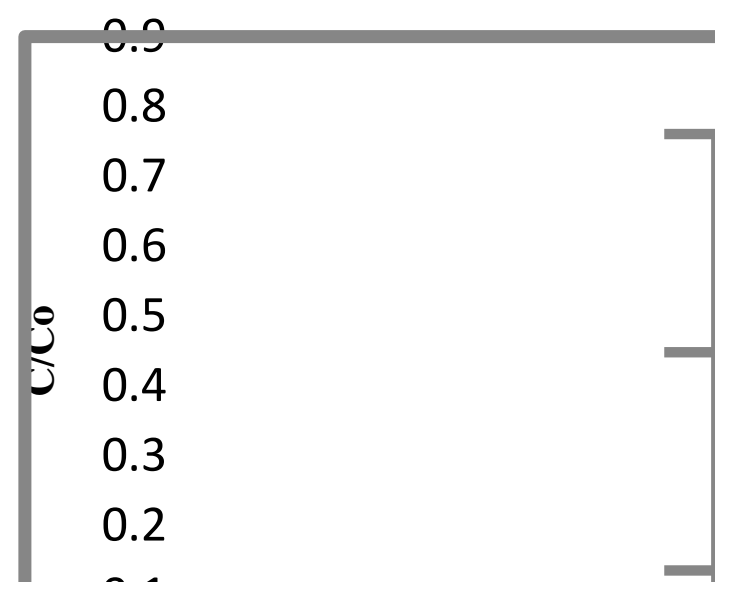

Figure 3.7.Break through curve for single adsorption of phosphate on black soil

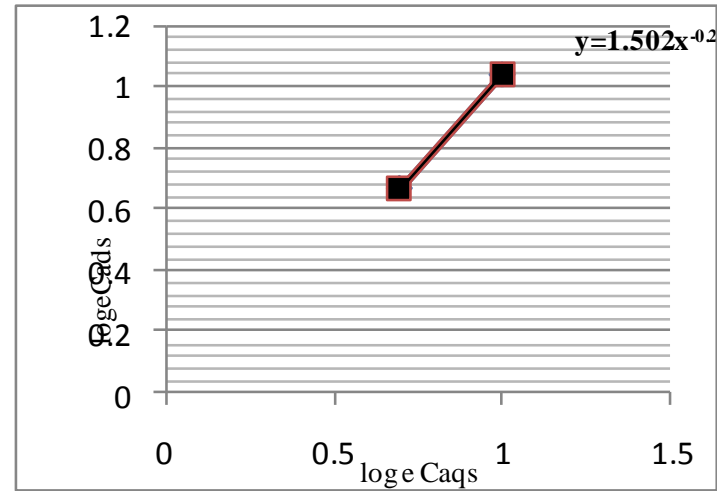

Figure 3.8. Freundlich isotherm of single adsorption of phosphate on black soil

Where $\mathrm{y}=1.502 \mathrm{x}^{-0.2}$ which is of the form $C_{a d s}=K^{F} \times C_{a q}^{1 / n}$ Where from "equation (4.1)" we get $\mathrm{K}^{\mathrm{F}}=1.502$ and $1 / \mathrm{n}=-0.2$ and from "equation 8 " we get $K_{d}^{F}=0.995$ from "equation (9)"we get retardation value as: $\mathrm{R}=2.892$

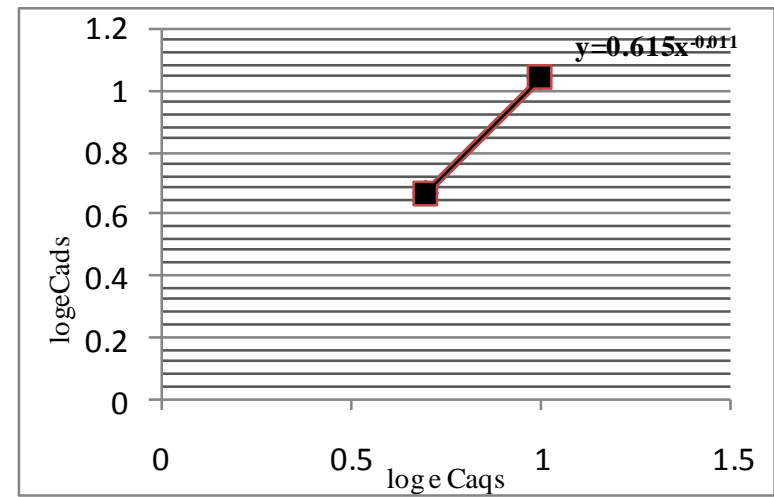

Figure 3.9. Langmuir isotherm of single adsorption of phosphate on black soil 
Table 3.2. Single adsorption of phosphate for selected concentrations and soils to fit langmuir isotherm

\begin{tabular}{|c|c|c|}
\hline Initial conc. & Black cotton soil mg/L & Red soil in mg/L \\
\hline $1 / \mathrm{C}$ & $1 / \mathrm{Q}$ & $1 / \mathrm{Q}$ \\
\hline 0.2 & 0.0212 & 0.0128 \\
\hline 0.1 & 0.0118 & 0.00525 \\
\hline
\end{tabular}

Table 3.3. Single adsorption of phosphate for selected concentrations and soils to fit Freundlich isotherm

\begin{tabular}{|c|c|c|}
\hline $\begin{array}{c}\text { Initial conc. } \\
\mathrm{mg} / \mathrm{L} \mathrm{C}\end{array}$ & Black cotton soil $\mathrm{mg} / \mathrm{L} \mathrm{C}_{\mathrm{ads}}$ & Red soil mg/L $\mathrm{C}_{\mathrm{ads}}$ \\
\hline 5.0 & 4.2 & 4.2 \\
\hline 10.0 & 9.998 & 9.997 \\
\hline
\end{tabular}

\section{CONCLUSION}

A series of Batch and Soil column tracer experiments have been performed in the laboratory for adsorption of Phosphate in Red \& Black cotton soils and the results are fit with analytical isotherms. The conclusions from the study can be summarized as follows:

It's evident from the characteristics properties that Black cotton soil and Red Soil are good adsorbent for removing Phosphate and these adsorbents are easily and cheaply available. Kinetic study indicated that adsorption of Phosphate is very rapid up to and decrease while approaching equilibrium. The rate of adsorption of Phosphate obeys first order rate equation. In batch experiments studies adsorption of Phosphate follows Freundlich and Langmuir isotherms indicating single adsorption of Phosphate and proves to be a favorable adsorption. Batch experiment results have clearly shown a different behavior in the two studied adsorbents .In this Black cotton Soil has shown maximum adsorption for Phosphate compared to Red Soil. It was observed that the maximum amount of Phosphate was leached through Black cotton Soil followed by Red Soil. In column tracer experiments results of Langmuir isotherm and Freundlich isotherm holds good, because when we fit the results to isotherms it gives equilibrium parameter $\mathrm{R}<1$ and $1 / \mathrm{n}<1$ respectively.

\section{REFERENCES}

[1] M.Del Bubbaa,, C.A. Ariasb, H. Brixc A Department of Chemistry, University of Florence, Via della Lastruccia 5, Sesto Fiorentino, Florence 50019, Italy Department of Hydraulics, Maritime and Environmental Engineering, Polytechnic University of Catalunya, Av. Gran Capit " a s/n, D1, Barcelona 08034, Spain Department of Plant Ecology, University of Aarhus, Nordlandsvej 68, Risskov DK8240, Denmark Received 26 February2002; accepted 28 March 2003

[2] Sardi \& Csatho1 et al "Studies on the phosphorous adsorption of different soil types of nutrient levels." 17th WCSS,14-21 August 2002,Thailand page.

[3] Anderson, A and G. Siman." Levels of Cd and some other trace elements in soils and crops as influenced by lime and fertilizer level". Acta - Agriculture Scandinavica. (1991).

[4] DEUTSCH W. J. "Groundwater geochemistry, fundamentals and applications to contamination" (1997): page, 47-55. Lewis Publisher. New York.

[5] Younger, P.L., Banwart, S.A., and Hedin, R.S. Mine Water: Hydrology, Pollution, Remediation, Kluwer Academic Publishers, Dordrecht (ISBN 1-4020-0137-1) (2002), page, 464. zakharova, t. and leitao, t.e- "Risks of Contamination of Groundwater by Heavy Metals

[6] Ayaz Mehmood, Mohammad Saleem Akhtar and Mehruinsa Memon Department of Soil Science \& Water Conservation, "Phosphorous adsorption parameters in relation to soil characteristics".,PMAS-Arid Agriculture University Rawalpindi, Pakistan ,vol 32, No 2,2010,129-139.

[7] QualityCriteria for Water, U.S. Environmental Protection Agency, EPA\#440/5-86-001, 1986.

[8] APPELO C.A.J. and POSTMA D- Geochemistry, Groundwater and Pollution". A.A. Balkema publishers, The Netherlands, (1996), page- 535 . 